\title{
Litterfall and Leaf Area Index in the CONECOFOR Permanent Monitoring Plots
}

\author{
Andrea CUTINI \\ Istituto Sperimentale per la Selvicoltura, Viale S. Margherita 80, 52100 Arezzo, Italy \\ e-mail: cutini@selvicoltura.org
}

\begin{abstract}
Forest canopies are more sensitive and react more promptly to abiotic and biotic disturbances than other stand structural components. Monitoring crown and canopy characteristics is therefore a crucial issue for intensive and continuous monitoring programs of forest ecosystem status. These observations formed the basis for the measurement of annual litter production and leaf area index (LAI) in the Italian permanent monitoring plots (CONECOFOR program) established within the EC-UN/ECE program "Intensive Monitoring (Level II) of Forest Ecosystems". Preliminary results after three years of observation are presented. The low value of within plot mean relative standard deviation $(20.8 \pm 1.9 \%)$ of litter production, which in any case never exceeded $30 \%$, accounted for the good sampling error and accuracy of the chosen method, which seems to be accurate enough to detect changes in litter production through the years. The higher inconsistency of the amount of woody and fruits fractions over the years demonstrated the greater reliability of leaf fraction or, on the other hand, of LAI compared to total litter. Mean values of annual leaf-litter and total litter production and LAI were rather high in comparison with data reported in literature for similar stands, and reflected both a medium-high productivity and a juvenile phase in the development of the selected stands on average. Focusing on changes in litter production through the years, statistical analysis on a sub-sample of plots showed the existence of significant differences both in leaf litter and total litter production. These findings seem to attribute to the "year" factor a driving role in determining changes in litter production and LAI. Temporal intermittence in data collection, together with the shortness of the monitoring period, make it difficult to speculate or arrive at definitive conclusions on changes in litter production due to time-dependent factors. The importance of having a complete database to increase index representativeness and reliability and, on the other hand, of performing an integrated results analysis which takes into account the outcomes of other research actions, is recognized as an indispensable requirement for achieving the goals of the monitoring program.
\end{abstract}

Key words: intensive monitoring, leaf area index, litter production, response indicators, integrated analysis

\section{INTRODUCTION}

Leaves and crowns are the active interface of energy, carbon and water exchanges between forest canopies and the atmosphere. Studies on the properties and productivity of crowns and canopy are therefore important in evaluating the quality of an ecosystem and its functional status (Waring 1983; Romane 1995).

Many investigators have analyzed the relationships between crown and canopy characteristics and abiotic and biotic disturbances such as extremes in the weather, atmospheric pollution and insect attacks. Waring (1985) hypothesized that reductions in canopy leaf area should accompany the chronic stress induced by air pollution, while Aber et al. (1989) theorized that an initial response of a forest to chronic nitrogen deposition would be a gradual increase in foliar biomass later followed by a decrease as the forest declined. Several other studies pointed out that growth efficiency was affected by environmental stress and acid deposition-induced imbalance of nitrogen and magnesium, and that a low growth efficiency increases susceptibility to insect attacks (Waring et al. 1980; Waring \& Pitman 1985; Oren et al. 1988). More generally, crowns and canopy seem to be more sensitive and react more promptly to disturbances than other stand structural components. Hence, monitoring crown and canopy characteristics would appear to be a crucial issue for intensive and continuous monitoring programs of forest ecosystem status.

It is in this context that Italy, in common with other European countries, decided to undertake surveys on the properties and productivity of crowns and canopies in forest ecosystems. This action is in addition to the mandatory surveys prescribed within the EC-UN/ECE program "Intensive Monitoring (Level II) of Forest Ecosystems", issued under Regulation 1091/94 on the longterm monitoring of forests "ICP-Forests" (Allavena et al. 1999). Leaf area index (LAI, projected leaf area per unit of ground area) and annual litter production were chosen as variables suitable for monitoring the properties and productivity of crowns and canopy. The leaf component of a canopy may in fact be quantified by its structural attribute, LAI. This important parameter regulates a number of ecophysiological processes, such as evapotranspiration and photosynthesis; hence, it is related to stand productivity (Gholz 1982; Waring 1983; Bolstad \& Gower 1990; Chason et al. 1991). More generally, canopy productivity may be quantified by litterfall or more precisely by annual litter production, which is also the major pathway for both energy and nutrients

Paper prepared within the CONECOFOR programme, by the contract with the Ministry for Agriculture and Forestry Policy - National Forest Service, Italy. CONECOFOR is part of the Pan-European Level II Intensive Monitoring of Forest Ecosystem and is co-sponsored by the European Commission. 
transfer in forest ecosystems (Bray \& Gorham 1964). Furthermore, both LAI and annual litter production largely meet the main requirements of a good indicator, in that they are quite simple, comprehensible, able to show time trends, reactive to environmental constraints, and amenable to comparison (Benedetti \& De Bertoldi 2000). With reference to this latter point, they were deemed able to interact well with the outcomes of other actions planned in the monitoring program, such as meteorological and phenological observations, crown condition assessment, and increment studies, so that they may be considered of more assistance than other variables in the formulation of a general analysis and understanding of the phenomena under observation.

A first report of the type of data available on the properties and productivity of crowns and canopy for the EC-UN/ECE Intensive Monitoring (Level II) of Forest Ecosystems plots in Italy (CONECOFOR programme) was given in Cutini (2001). This paper shows the results on litter production and LAI which emerged after three years of observation, and discusses their meaning and potential use with reference to the general aims of the monitoring programme. Emphasis is given to an evaluation of the accuracy of the methods adopted to estimate litter production and LAI, in relation to yearto-year variations and changes in litter production and LAI. In fact, the role of stochastic events and non-polluting factors cannot be ignored in the detection of changes due to polluting factors; rather, they must be accounted for before the effects of air pollution can be determined (Miller 1986; Grier 1988).

\section{METHODS}

Surveys began in the second half of 1997 and involved nineteen of the twenty permanent intensive (level II) monitoring plots representing the original network of the CONECOFOR program and covering the commonest forest types found in Italy. Details of sampling strategy, plot representativeness and stand characteristics are given in Allavena et al. (1999) and Fabbio \& Amorini (2001).

Twelve $0.25 \mathrm{~m}^{2}$ litter-traps were positioned systematically in each plot to estimate the total annual litter production (dry biomass) and its main fractions, according to the method described by Cutini (1992). Litter was collected every fifteen days during fall and once a month during the other seasons. Local offices of the National and Regional Forest Service were responsible for the collection of samples, and also sent material to our laboratories for analysis. In some cases ${ }^{1)}$ (ABR1, LOM1, TOS1 plots) the collected material was analysed by other research institutions, which also provided data processing. The contents of each trap were weighed (ambient air-drying status) all together before being sorted, to assess variability among collectors within plots. The litter was then sorted into the main fractions (leaves of main species and of accompanying species, woody parts and fruits), pooled for each plot and then dried in a forced air stove at $85^{\circ} \mathrm{C} \pm 2$ until a constant dry weight was reached. The litter was distinguished into the following main fractions for data processing: leaf (LL, total amount of leaves of all species present in the plot), fruits and woody parts.

The direct measurement of LAI in forest ecosystems often presents insurmountable difficulties in practice, so that much effort has gone into devising indirect methods. Of these, the ones based on radiative techniques are the most promising. They rely on the dependency between canopy structure and the gap fraction of the canopy (Lang 1986; Welles 1990). One of the most popular systems for measuring gap fraction and thus for obtaining estimates of the stand LAI is the LAI-2000 Plant Canopy Analyzer (Li-Cor, Lincoln, NE, USA). This instrument uses diffuse light interception to provide estimates both of the quantitative characteristics of the canopy as LAI and of foliage arrangement and distribution in space, and can be successfully used to assess both temporal and spatial variations and to compare different stands (Cutini et al. 1998). It was used on a sub-sample of fifteen plots in the CONECOFOR network. LAI (LAIpca) was measured during the period of maximum leaf expansion (July-August) in 1997 and 1998. Measurements were taken over the litter-traps according to a protocol already described (Cutini et al. 1998). Besides litter production and LAIpca, other potentially interesting variables or indicators such as mean leaf area, mean leaf dry weight, specific leaf area (SLA) and LAI calculated from litterfall were measured. Results of these measurements will be analyzed at a later date.

All the statistical comparisons were performed using Friedman ANOVA (Statistica, Statsoft ${ }^{\circledR}$ Inc.).

\section{RESULTS}

The original data collection plan had to be modified after two years due to financial constraints involving the monitoring program. This led to a progressive reduction in the number of surveyed plots, and to the re-arrangement and simplification of data collection procedures. Temporal intermittence in data collection or, in some cases, an absence of data, dictated the expedient of articulating the data analysis and presentation of results into three levels of detail. The first level involved as great a number of plots and species as possible, to give a general picture of the variables measured. The second step was performed at forest type-based level, grouping plots into four main categories: pure stands of Norway spruce (Picea abies) or stands with Norway spruce as main species (PA, four plots); pure stands of beech (Fagus sylvatica) or stands with beech as main species (FS, seven plots); pure stands of Turkey oak (Quercus

\footnotetext{
1) Data from ABR 1, LOM 1 and TOS 1 plots were provided by Department of Forest Environment and Resources - University of Tuscia, Department of Plant Biology - University of Florence and Lombardy Regional Forest Estate - Milan, respectively.
} 
Tab. 1. Statistics (mean \pm s.e.) of litter production $\left(\mathrm{Mg} \mathrm{ha}^{-1}\right.$, total and main fractions) observed during the period 1998-2000 in the intensive (level II) monitoring plots of the CONECOFOR program. * Data provided by other institutions (see the text). ${ }^{* *}$ stored coppices undergoing conversion into high forest. One or more thinnings carried out in the original stored crops.

\begin{tabular}{|c|c|c|c|c|c|c|c|}
\hline \multirow[t]{2}{*}{ Plot } & \multirow[t]{2}{*}{ main species } & \multirow[t]{2}{*}{ manag. system } & \multirow[t]{2}{*}{ n. years } & \multicolumn{4}{|c|}{ litter } \\
\hline & & & & leaf & woody & fruits & total \\
\hline FRI 1 & C. betulus & stored coppice & 3 & $4.538 \pm 0.244$ & $1.168 \pm 0.441$ & $0.437 \pm 0.085$ & $6.143 \pm 0.573$ \\
\hline ABR $1 *$ & F. sylvatica & high forest & 3 & $2.969 \pm 0.354$ & $0.904 \pm 0.900$ & 0.030 & $3.884 \pm 1.228$ \\
\hline CAL 1 & F. sylvatica & high forest & 2 & $4.644 \pm 0.446$ & $0.398 \pm 0.029$ & $1.534 \pm 1.887$ & $6.577 \pm 2.304$ \\
\hline CAM 1 & F. sylvatica & high forest & 1 & 2.295 & 0.178 & 3.020 & 5.493 \\
\hline EMI 2 & F. sylvatica & stored coppice & 1 & 2.370 & 0.546 & 0.090 & 3.006 \\
\hline PIE 1 & F. sylvatica & stored coppice & 3 & $2.964 \pm 0.116$ & $1.850 \pm 1.775$ & $0.080 \pm 0.050$ & $4.894 \pm 1.797$ \\
\hline PUG 1 & F. sylvatica & high forest & 3 & $4.172 \pm 0.833$ & $0.550 \pm 0.155$ & $1.162 \pm 1.358$ & $5.886 \pm 1.827$ \\
\hline VEN 1 & F. sylvatica & high forest & 3 & $2.318 \pm 0.475$ & $0.504 \pm 0.107$ & $0.083 \pm 0.040$ & $2.906 \pm 0.484$ \\
\hline FRI 2 & P. abies & high forest & 1 & 4.587 & 0.297 & 0.232 & 5.116 \\
\hline LOM $1 *$ & P. abies & high forest & 1 & 2.556 & 0.439 & 0.200 & 3.195 \\
\hline TRE 1 & P. abies & high forest & 3 & $2.171 \pm 0.196$ & $0.605 \pm 0.186$ & $0.741 \pm 0.118$ & $3.518 \pm 0.299$ \\
\hline VAL 1 & P. abies & high forest & 1 & 2.911 & 0.475 & 0.056 & 3.442 \\
\hline BAS 1 & Q. cerris & trans. crop** & 3 & $3.973 \pm 0.776$ & $0.572 \pm 0.230$ & $0.392 \pm 0.172$ & $4.938 \pm 1.129$ \\
\hline EMI 1 & Q. cerris & stored coppice & 3 & $4.271 \pm 0.181$ & $1.867 \pm 0.490$ & $0.401 \pm 0.224$ & $6.539 \pm 0.748$ \\
\hline LAZ 1 & Q. cerris & stored coppice & 3 & $3.510 \pm 0.585$ & $0.503 \pm 0.089$ & $0.068 \pm 0.023$ & $4.082 \pm 0.694$ \\
\hline MAR 1 & Q. cerris & stored coppice & 3 & $3.866 \pm 0.485$ & $0.866 \pm 0.219$ & $0.520 \pm 0.431$ & $5.253 \pm 0.542$ \\
\hline SIC 1 & Q. cerris & stored coppice & 2 & $4.997 \pm 1.331$ & $2.059 \pm 0.459$ & $0.791 \pm 0.086$ & $7.847 \pm 1.876$ \\
\hline SAR 1 & Q. ilex & stored coppice & 3 & $3.506 \pm 0.982$ & $1.185 \pm 0.372$ & $1.115 \pm 0.219$ & $5.806 \pm 1.034$ \\
\hline TOS $1 *$ & Q. ilex & stored coppice & 2 & $4.548 \pm 1.344$ & $1.666 \pm 0.570$ & $1.295 \pm 0.522$ & $7.510 \pm 1.393$ \\
\hline
\end{tabular}

cerris), or mixed stands of Turkey oak and other deciduous species such as sessile oak (Quercus petraea) and hornbeam (Carpinus betulus) (QC, six plots); pure stands of holm oak (Quercus ilex) or stands with holm oak as main species (QI, two plots). The third level of detail, designed to reveal possible indications of changes in this relatively short period, took into account only plots with a complete data set. As a consequence, statistical analyses were performed only on FS (three plots) and QC (five plots).

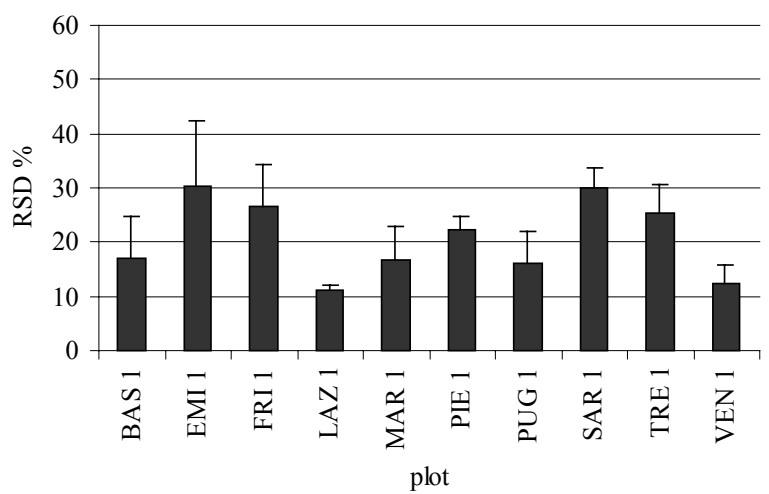

Fig. 1. Within plot relative standard deviation (RSD, mean + s.e.) of total litter production through the period 1998-2000 in the intensive (level II) monitoring plots of the CONECOFOR program.

The overall results for each permanent monitoring plot, in terms of mean annual litter production (dry weight), total and main fractions, are given in table 1. A complete data set was available for eleven plots; in three and five cases this was available for two years and one year, respectively.
Measurements on total litterfall at ambient air-drying status made it possible to evaluate within plot variability separately for each year of observation. The overall mean $( \pm$ s.e. $)$ of relative standard deviation (RSD, standard deviation-to-mean ratio or coefficient of variation as percentage) was $20.8 \% \pm 1.9$, with an absolute minimum value of $7.1 \%$ (PUG 1 plot, 2000) and a maximum of $48.4 \%$ (EMI 1 plot, 1998). In no case did the mean RSD of each plot exceed 30\% (Fig. 1).

As regards the LAI measured with PCA LAI 2000, the data available for 1997 and 1998 are reported in figure 2 .

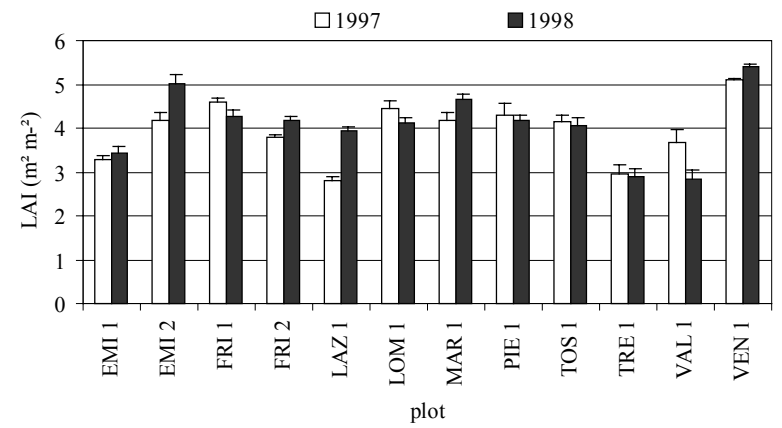

Fig. 2. LAI (mean + s.e.) measured with PCA LAI 2000 in the intensive (level II) monitoring plots of the CONECOFOR program.

The RSD in litter production between years (1998, 1999,2000 ) ranged between 5.5\% (PIE 1 plot) and $39.6 \%$ (SAR 1 plot) for the leaf component, the mean being $20.0 \%$. The RSD of total litter ranged between $12.0 \%$ (TRE 1 plot) and $51.9 \%$ (PIE 1 plot), with a mean of $27.1 \%$ (Fig. 3). 
Tab. 2. Statistics (mean \pm s.e.) of leaf and total litter production, leaf fraction (period 1998-2000) and LAI (period 1997-1998) measured with PCA LAI 2000 in the intensive (level II) monitoring plots of the CONECOFOR program belonging to different forest types.

\begin{tabular}{lcccc}
\hline & \multicolumn{3}{c}{ litter } & LAI \\
\cline { 2 - 4 } & $\begin{array}{c}\text { leaf } \\
\left(\mathrm{Mg} \mathrm{ha}^{-1}\right)\end{array}$ & $\begin{array}{c}\text { total } \\
\left(\mathrm{Mg} \mathrm{ha}^{-1}\right)\end{array}$ & $\begin{array}{c}\text { leaf fraction } \\
(\%)\end{array}$ & \begin{tabular}{c}
$\left(\mathrm{m}^{2} \mathrm{~m}^{-2}\right)$ \\
\hline P. abies
\end{tabular} $2^{2.732 \pm 0.358}$ \\
Fylvatica & $3.181 \pm 0.281$ & $4.756 \pm 0.546$ & $78.0 \pm 7.9$ & $3.6 \pm 0.5$ \\
Q. cerris & $4.142 \pm 0.202$ & $5.688 \pm 0.382$ & $75.5 \pm 5.8$ & $4.8 \pm 0.2$ \\
Q. ilex & $3.793 \pm 0.596$ & $6.281 \pm 0.633$ & $60.5 \pm 3.5$ & $3.9 \pm 0.2$ \\
\hline
\end{tabular}

The mean RSD for leaf litter and total litter production of FS and QC, the two most important forest types, are shown in figure 4. Friedman ANOVA revealed the existence of significant differences $(\mathrm{P}<0.05)$ for total litter only.

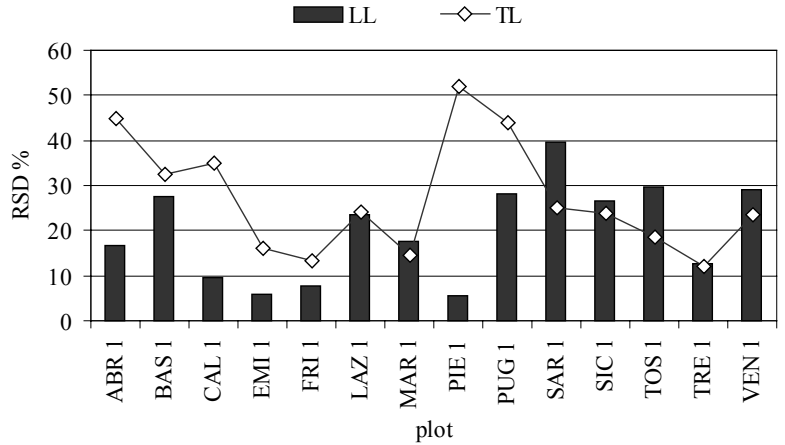

Fig. 3. Relative standard deviation (RSD) of leaf litter (LL) and total litter (TL) production through the period 1998-2000 in the intensive (level II) monitoring plots of the CONECOFOR program.

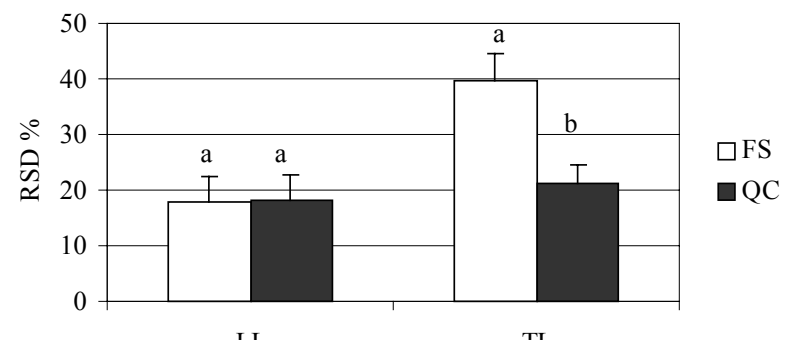

LL

TL

Fig. 4. Relative standard deviation (RSD, mean + s.e.) of leaf (LL) and total litter (TL) production through the period 19982000 in FS (beech plots) and QC (Turkey oak and other species) intensive monitoring plots of the CONECOFOR program. Means with different letters differ significantly at $p$ $<0.05$ level.

Comparisons of average productivity and stand structure of the main forest types may be made on the basis of table 2, which reports mean leaf-litter production, total litter production, leaf-to-total litter ratio (leaf fraction, \%) and LAI, measured with PCA LAI 2000 (LAIpca).
For the reason reported above, a more detailed analysis of data aimed at detecting changes occurring during the observation period was carried out at forest type-based level. Figure 5, in which leaf litter and total litter values are plotted vs the three years of observation, shows, with the sole exception of QI, how both variables followed the same pattern, with the 1999 values lower than those of 1998 and 2000. Statistical analysis on FS and QC pooled data (eight plots) with Friedman ANOVA showed a significant $(\mathrm{P}<0.05)$ influence of the year factor on leaf litter and total litter production, with the 1999 mean figures lower than those of 1998 and 2000 (Fig. 6).

\section{DISCUSSION AND CONCLUSIONS}

The within plot variability of litter production, which was on average $20 \%$ and never exceeded $30 \%$, accounted for the good sampling error and accuracy of the chosen method and led to a positive general evaluation of the experimental protocol adopted after three years of observation. This conclusion appears to be justified when other studies are taken into account (Burton et al. 1991; Cutini 1992) and considering that the RSD observed in this study are considerably lower than $50 \%$, which is generally the threshold for regarding as acceptable results obtained in similar studies.

This positive result does not by itself mean that the adopted protocol can detect changes in total litter or in litter fractions on a temporal scale. With regard to the question of whether the measurements are sufficiently accurate, the limited number of datasets makes it difficult to arrive at any definitive conclusion. However, although the accuracy of the measurements has been proved only for fresh total litter, it is reasonable to suppose that dry total litter was subject to a similar variability, as were its fractions, at least in part. Starting from this assumption, on the basis of results available after three years of observation, the measurements seem to be accurate enough to detect changes of litter production on a temporal scale. Indeed, the variability among years of total litter RSD (27.1\%) was higher than the within plot sampling error. Furthermore, it must be stressed that cases with a sampling error exceeding $30 \%$ have been registered in years characterized by an abnormal production of woody parts or fruits. This could 
P A

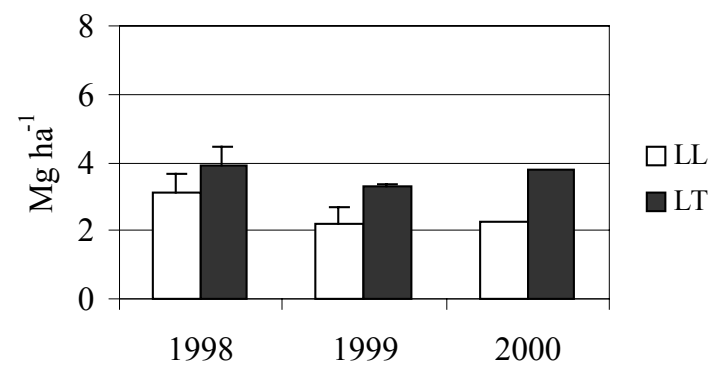

F S

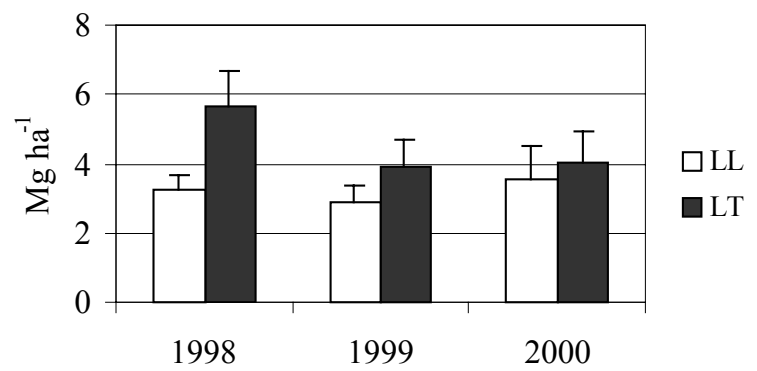

Q C

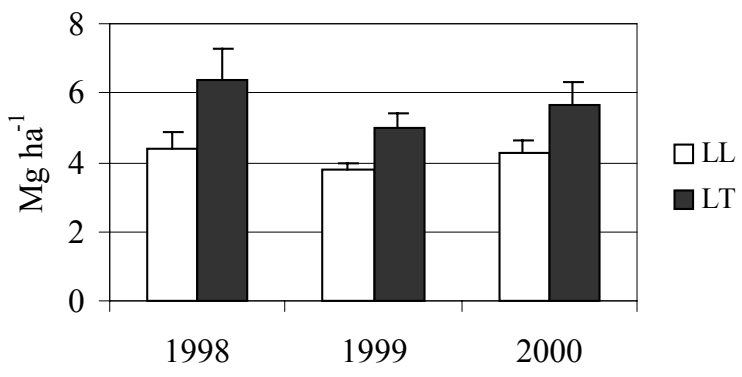

Q I

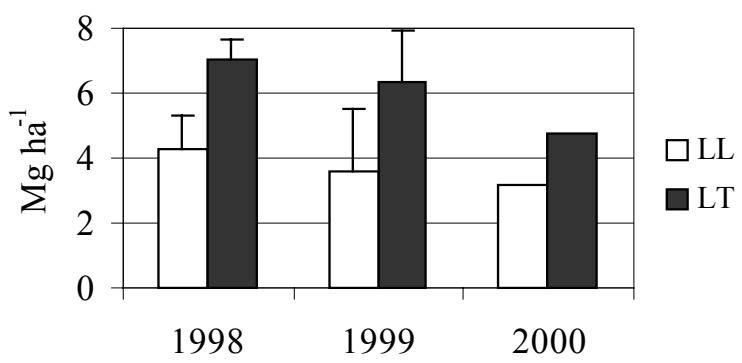

Fig. 5. Mean ( \pm s.e.) leaf and total litter production (LL and TL, respectively) through the period 1998-2000 in Picea abies (PA), Fagus sylvatica (FS), Quercus cerris (QC) and Quercus ilex (QI) intensive monitoring plots of the CONECOFOR program.

explain why, in a comparison between FS and QC, the two most important forest types, leaf litter variability was practically the same, while significant differences were observed for total litter.

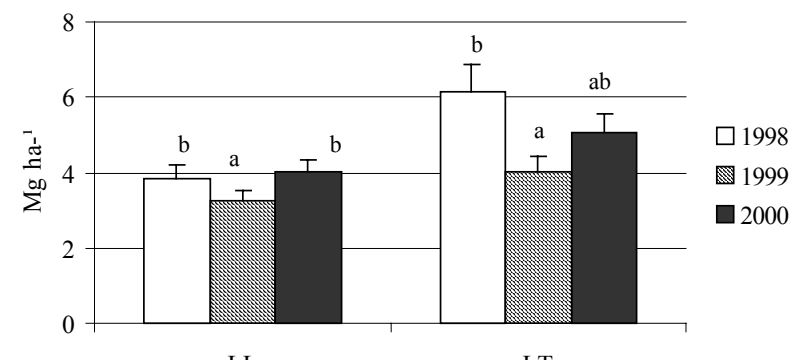

LL

LT

Fig. 6. Mean (+ s.e.) leaf and total litter production (LL and LT, respectively) through the period 1998-2000 in beech and Turkey oak intensive monitoring plots (pooled data) of the CONECOFOR program. Means with different letters differ significantly at $\mathrm{p}<0.05$ level.

From a general point of view, the varaiability of the woody and fruits fractions among years seems to demonstrate the greater reliability of leaf fraction or, on the other hand, of LAI, compared to total litter.

As regards productivity, the selected stands were on the whole characterized by good performances. It must be noted that mean values of annual leaf-litter and total litter production, calculated at forest type-based level, were rather high if compared with data reported in literature. On average, for temperate forest, total annual litter production ranges from 3.5 to $5.5 \mathrm{Mg} \mathrm{ha}^{-1}$ and leaf litter from 2.5 to $3.6 \mathrm{Mg} \mathrm{ha}^{-1}$ (Bray \& Gorham 1964; O’Neil \& De Angelis 1981). These findings are consistent with measurements from PCA LAI 2000, which although generally underestimating the true value, yielded LAI figures ranging from 3 to $5.5 \mathrm{~m}^{2} \mathrm{~m}^{-2}$.

In addition, selected stands seem to be on average in a juvenile phase of stand dynamics. This can be deduced from leaf fraction values which, though similar to those reported in literature for temperate forests (Jarvis and Leverenz 1983), are considerably higher (60-75\%) than those commonly observed in mature stands (50-55\%), generally characterized by a greater proportion of nonleaf litter (Kira \& Shidei 1967).

Turning to the analysis of data on a temporal scale, LAI measurements did not reveal significant differences. Furthermore, the monitoring period $(1997,1998)$ was different from that of litter production (1998-2000), so that further comparison was impossible. If the analysis is limited to FS and QC plots, it will be seen that in three out of four cases LAI was higher in 1998 than in 1997. In any case, we can agree with the conclusions emerging from other experiences of forest condition monitoring, which emphasized that continuous LAI estimates with LAI 2000 on a number of plots would produce an interesting time series on the variations in LAI and provide useful information for interpreting the state of a forest ecosystem (Smolander et al. 2000).

Conversely, the analysis of litter production was more profitable, with the exception of QI, whose pattern inconsistency could be partly explained by the ever- 
green habit of the species. Both leaf litter and total litter of PA, FS and QC showed the same trend during the observation period, with 1999 values lower than those of 1998 and 2000. Furthermore, statistical analysis on a restricted number of plots belonging to FS and QC forest types highlighted significant differences in both leaf litter and total litter production. These findings seem to attribute to the "year" factor a driving role in determining changes in canopy properties and productivity.

Unfortunately, the lack of data in some cases, coupled with the shortness of the monitoring period, does not at present allow any further and more satisfactory analysis of results. This prevents any particular speculation or definitive conclusion as regards changes in litter production due to time-dependent factors or factors varying on a temporal scale, such as climate and pollution. In fact, findings on the magnitude of the impact of pollution on canopy characteristics are at the moment poorly known. This makes it difficult to detect statistically verifiable effects of pollution on canopy characteristics, which may be lost in the "noise" created by the vagaries of nature such as heavy seed years or changes due to the normal fluctuation of climatic conditions (Burton et al. 1991).

However, while further analyses are evidently necessary, these first results confirm both litter production, i.e. leaf litter, and LAI, as indicators able to show time trends and react to environmental changes. Their continuous monitoring over time could provide not only knowledge of the structure and functional status of the selected stands, but also a better understanding of the real impact of factors such as atmospheric pollution, extremes in the weather and incidence of insect attacks (Jarvis \& Leverenz 1983).

To facilitate the achievement of this objective, it is important that results regarding litter production and LAI should interact and be combined with the outcome of other actions (Cutini 2001). In this connection, coupling datasets on litter and LAI with meteorological and phenological observations, crown condition assessment and increment studies is a step that must not be delayed.

\section{ACKNOWLEDGMENTS}

The Author wishes to thank all the local-based National and Regional Forest Service officers and technicians who assisted with field data collection, and the Department of Forest Environment and Resources University of Tuscia, the Department of Plant Biology University of Florence and the Lombardy Regional Forest Estate for providing their own data. Special thanks to my colleagues at the Istituto Sperimentale per la Selvicoltura, C. Benvenuti, U. Cerofolini, M. Ceccarelli, V. Giulietti, L. Mencacci and M. Piovosi, who allowed the implementation of the experimental trial, and assisted with data collection and laboratory analyses, to Fiona Tatò for the English revision and one anonyimous reviewer for the helpful comments.
This work has been carried out in the framework of the Italian Program For Forest Ecosystems Monitoring (CONECOFOR)

\section{REFERENCES}

Aber, J.D., K.J. Nadelhoffer, P. Steudler \& J.M. Melillo 1989. Nitrogen saturation in northern forest ecosystems. BioScience, 39: 378-386.

Allavena, S., R. Isopi, B. Petriccione \& E. Pompei 1999. Programma Nazionale Integrato per il controllo degli ecosistemi forestali. Ministero delle Politiche Agricole, Roma, Italia: $220 \mathrm{pp}$.

Benedetti, A. \& S. De Bertoldi 2000. Qualità del suolo: criteri di definizione. Relazione al Convegno Accademia Nazionale delle Scienze, 29 marzo, Roma.

Bolstad, P.V. \& S.T. Gower 1990. Estimation of leaf area index in fourteen southern Wisconsin forest stand using a portable radiometer. Tree Physiology, 7: 115-124.

Bray, J.R. \& E. Gorham 1964. Litter production in forests of the world. Adv. Ecol. Res., 2: 101-157.

Burton, A.J., K.S. Pregitzer \& D.D. Reed 1991. Leaf area and foliar biomass relationships in Northern hardwood forests located along an $800 \mathrm{~km}$ acid deposition gradient. Forest Science, 37: 1041-1059.

Chason, J.W., D.D. Baldocchi \& M.A. Huston 1991. A comparison of direct and indirect methods for estimating forest canopy leaf area. Agric. For. Meteorol., 57: 107128.

Cutini, A. 1992. Indice di area fogliare, produzione di lettiera ed efficienza di un ceduo di cerro in conversione. Ann. Ist. Sper. Selv., Arezzo (Italy), XXIII: 147-166.

Cutini, A. 2001. Properties and productivity of crowns and canopy. Contribution to an integrated analysis of forest ecosystems status. Ann. Ist. Sper. Selv., Arezzo (Italy) 30: 91-97.

Cutini, A., G. Matteucci \& G. Scarascia Mugnozza 1998. Estimation of leaf area index with the Li-Cor LAI 2000 in deciduous forests. For. Ecol. Manage., 105: 55-65.

Fabbio, G. \& E. Amorini 2001. Tree growth survey and increment assessment. Contribution to the integrated evaluation of ecosystem's status. Ann. Ist. Sper. Selv., 30: 81-89.

Gholz, H.L. 1982. Environmental limits on aboveground net primary production, leaf area and biomass in vegetation zones of the Pacific Northwest. Ecology, 63: 469-481.

Grier, C.C. 1988. Foliage loss due to snow, wind, and winter drying damage: its effect on leaf biomass of some western conifers. Can. J. For. Res., 18: 1097-1102.

Jarvis, P.G. \& J.W. Leverenz 1983. Productivity of temperate, deciduous and evergreen forests. In: O.L. Lange et al. (Eds), Physiological plant ecology. IV. Encyclopedia of Plant Physiology. New Series, 12D: 233-280.

Kira, T. \& T. Shidei 1967. Primary production and turnover of organic matter in different forest ecosystems of the western Pacific. Jpn. J. Ecol., 17: 70-87.

Lang, A.R.G. 1986. Leaf area and average leaf angle from transmission of direct sunlight. Australian Journal of Botany, 34: 349-355.

Miller, H.G. 1986. Carbon $\mathrm{x}$ nutrient interactions - the limitation to productivity. Tree physiol., 2: 373-385.

O’Neil, R.V. \& D.L. De Angelis 1981. Comparative productivity and biomass relations of forest ecosystems. In: D.E. Reichle (Ed.), Dynamic properties of forest ecosystems. Cambridge University Press, London: 441449.

Oren, R., E.D. Schulze, K.S. Werk \& J. Mayer 1988. Performance of two Picea abies (L.) Karst. stands at different stages of decline. VII. Nutrient relations and growth. Oecologia, 77: 163-173. 
Romane, F. 1995. Introduction and objectives. In: F. Romane (Ed.). Sustainability of Mediterranean ecosystems. Case study of the chestnut forest. European Commission, Brussels, Ecosystem research report 19: 1-5.

Smolander, H., P. Voipio \& B. Kleinhenz. LAI-2000 estimates as an indicator of forest vitality. In: L. Ukonmaanaho \& $\mathrm{H}$. Raitio (Eds), Forest condition monitoring in FinlandNational report 1999. Finnish Forest Research Institute, Research Papers 782: 79-89.

Waring, R.H. 1983. Estimating forest growth and efficiency in relation to canopy leaf area. Adv. Ecol. Res., 13: 327-354.
Waring, R.H. 1985. Imbalanced forest ecosystems: assessment and consequences. For. Ecol. Manage., 12: 93-112.

Waring, R.H. \& G.B. Pitman 1985. Modifying lodgepole pine stands to change susceptibility to mountain pine beetle attack. Ecology, 66: 889-897.

Waring, R.H., W.G. Thies \& D. Muscato 1980. Stem growth per unit leaf area: a measure of tree vigor. For. Sci., 26: 112-117.

Welles, J.M. 1990. Some indirect methods of estimating canopy structure. Remote Sensing Reviews, 5: 31-43. 